\title{
Bubble Departure Diameter Prediction Uncertainty
}

\author{
Marko Matkovič and Boštjan Končar \\ Jozef Stefan Institute, Jamova 39, 1000 Ljubljana, Slovenia \\ Correspondence should be addressed to Marko Matkovič, marko.matkovic@ijs.si
}

Received 25 May 2012; Accepted 11 December 2012

Academic Editor: Dominique Bestion

Copyright ( 2012 M. Matkovič and B. Končar. This is an open access article distributed under the Creative Commons Attribution License, which permits unrestricted use, distribution, and reproduction in any medium, provided the original work is properly cited.

\begin{abstract}
This paper presents quality assessment of a mechanistic modelling for bubble departure diameter prediction during pool boiling condition. In contrast to flow boiling process only buoyancy force with opposing surface tension force was considered as the responsible mechanisms for bubble departure. Indeed, inertia from the fluid flow around the bubble and the growth force, which describes momentum change due to the evaporation at the bubble base and condensation at the top of the bubble, were all neglected. Besides, shear lift force and quasi-steady drag force as the dominant inertia driven forces were also neglected in the assessment. Rather than trying to model bubble dynamics as precise as possible by properly addressing all the relevant mechanisms available, the work focuses on prediction accuracy of such approach. It has been shown that inlet boundary conditions with realistic experimental accuracy may lead to a significant uncertainty in the prediction of bubble departure diameter, which is intrinsically connected to the uncertainty of most heat partitioning and CHF models.
\end{abstract}

\section{Introduction}

Boiling process is so widely met in everyday life that one often forgets to deal with one of the most complex phenomena in energy and process engineering. Precise and accurate prediction of boiling heat transfer is crucial both in terms of rational use of energy as well as from the standpoint of safe operation of such systems. With reference to the nuclear engineering applications an accurate prediction of the governing mechanisms would have significantly decreased exergy losses during flow boiling heat transfer. A reliable prediction of the critical heat flux on the other hand could have not only increased the nominal power of the steam generators at PWR but it would have improved safety issues in those systems as well. Regarding boiling a significant amount of research activity has been carried out for the past 60 years mainly with the purpose of quantitative evaluation of the mechanisms involved. Many researchers studied heat transfer mechanisms at subcooled flow conditions and proposed the modelling approach that considers the flow boiling heat transfer as a superposition of the liquid-phase convective heat transfer and the evaporation heat transfer mechanisms $[1,2]$. Wall heat flux during the subcooled flow nucleate boiling was thus partitioned for different heat transfer mechanisms of the boiling process. In this context, part of the heat flux, which is responsible for evaporation, was studied profoundly through active nucleation sites and their surface density, and the frequency of bubble formation and their diameter at departure. There are quite some models available in the open literature for bubble growth and its diameter prediction at departure. Bubble departure diameter prediction, which was published by Fritz [3] for instance, takes into account a balance between buoyancy force and surface tension force only. One of the first models to determine maximum bubble volume is often inconsistent with experimental measurements particularly at high values of reduced pressures. Consequential development of new models often led to different or even conflicting influential parameters. Cole and Rohsenow [4] proposed correlation for calculation of bubble departure diameter at low pressure for boiling water and other liquids by introduction of the two distinct leading constants. They also introduced the bubble size dependence on the modified Jacob number. In search for efficient model for bubble departure diameter prediction Tolubinski and Kostanchuk [5] studied different surfaces and wall temperature overheating. While Kocamustafaogullari 
[6] tried to include various reduced pressures in his studies Gorenflo et al. [7] focused on high specific heat flow rates at elevated saturation pressure. They highlighted the significance of thermal diffusivity and Jacob number, but ignored the impact of the density ratio of competing phases. Despite extensive efforts by researchers to date rather modest progress has been achieved in identifying and predicting the growth mechanisms and dynamics of bubbles. The main reason for the lack of new knowledge is limited understanding of the temperature and velocity fields in the boiling boundary layer influenced by the bubble dynamics. There the parameters are evolving rapidly in time and space, which made these measurements inaccessible until recent time. Besides, wetting angle and the mutual interaction between the bubbles are also deficiently studied. On one hand there are new experimental techniques available for heat transfer and fluid flow measurements within wall boundary layer [8] while on the other hand new approaches based on direct numerical simulations seem to become more and more important for better understanding of the twophase flow and heat transfer mechanisms [9].

Aim of the present inquiry is the qualitative evaluation of the bubble departure diameter modelling. To start with, prediction uncertainty of bubble departure and bubble growth diameters during pool boiling test conditions has been analysed. Buoyancy with opposing surface tension force is here assumed to be the responsible mechanisms for bubble departure even though shear lift force and quasisteady drag force are believed the influential inertia driven forces as well. They act together with the buoyancy force against the surface tension force that is the only mechanism responsible for keeping the bubbles attached on the wall. In fact, bubble diameter tends to favour buoyancy force versus surface tension force. The bigger is the density ratio and the bigger is the gravity acceleration at reference surface tension, the smaller is the required bubble diameter at departure. However, the dominant inertia driven forces (shear lift force and quasi-steady drag force), as well as the growth force or so-called unsteady drag force, which describes momentum change due to evaporation at the bubble base and condensation at the top of the bubble, were all neglected in the assessment. At this point, rather than including all driving mechanisms for bubble modelling, the work focuses on the prediction accuracy of bubble departure diameter during the pool boiling phenomenon. Therefore, uncertainty analyses of bubble growth and bubble departure diameter modelling have been carried out.

\section{Modelling Background}

One of the key parameters for characterizing the flow boiling phenomenon is usually addressed to the diameter to which a bubble grows before departure. On this subject, a large number of correlations and mechanistic approaches have been proposed in the literature. Almost eight decades ago Fritz [3] calculated the maximum volume for vapour bubbles by compensating the buoyancy force that acts to lift the bubbles away from the heating surface with the surface tension force, which holds the bubbles attached on the surface. He formulated the two driving mechanisms and the surface wettability (contact angle $\phi$, given in ${ }^{\circ}$ ) in a rather simple correlation depicted in (1). The bubble departure diameter is increasing with the contact angle and with the surface tension while it decreases with gravity and density difference that define buoyancy potential. The expression in the square root is hereafter

$$
D_{\mathrm{BD}}=0.0208 \cdot \phi \cdot \sqrt{\frac{\sigma}{g \cdot\left(\rho_{l}-\rho_{v}\right)}}
$$

addressed the characteristic length. The importance of the contact angle (Figure 1) has been confirmed also experimentally several times. Most recently, Nam et al. [10] demonstrated by the use of superhydrophilic surface with artificial nucleation sites a significant decrease of bubble departure diameter with decreasing contact angle. In order to balance the evaporation rate with smaller bubbles their generation has to become more numerous. In fact, different wettability does not only affect the bubble departure diameter but it has a significant impact on the release frequency as well. Moreover, boiling surface and wall material to a certain depth have been shown to have an important role in heat partitioning during the boiling heat transfer and affect the occurrence of the critical heat flux phenomenon [11]. Figure 2 demonstrates how different contact angles affect bubble growth and bubble dynamics on boiling surfaces. In the absence of fluid motion the terminal diameter of a growing bubble (at a given contact angle) before departure from the boiling surface is obtained from the equilibrium of buoyancy and surface tension forces (Figure 2). Bubble departure diameter is yet to be deduced from the volume of the spherical cap of the growing bubble just before departure. Intuitively, the shallower the cap the bigger discrepancy between the size of the growing bubble and the bubble departure diameter is expected. Rather high void fraction is also expected in the near proximity to the liquid repellent surfaces as they spread the generated vapour on larger area. Intense wall superheat is therefore expected and may lead to an early occurrence of a dry-out phenomenon as the boiling surface encased in an insulated vapour blanket tends to remove heat less efficiently from the source compared to the well wetting surface.

Nevertheless, there are many other forces acting on the bubbles attached to the heating surface. If the liquid flows around the bubble two additional forces may appear instantaneously. Interphase drag presents the response of the bubble geometry on the wall to the resistance of the fluid flow. This force is proportional to a projected area of the vapour bubble in the direction of the flow, to the liquid density, to a drag coefficient, and to the square of the liquid velocity. Of course, any force that is acting on the vapour slug may distort its shape causing the drag coefficient and the projected area to change (Figure 3). On the other hand, the liquid flow above the vapour bubble induces also the lift force that acts perpendicular to the direction of the relative motion. Here, the presence of a rotational continuous phase plays an important role. Another important force during 


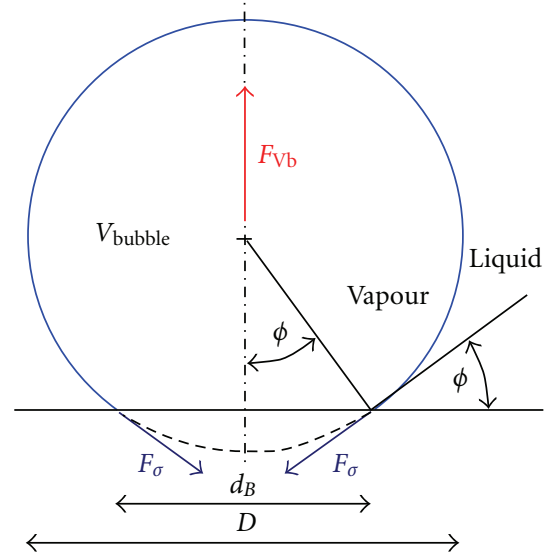

(a)

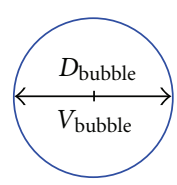

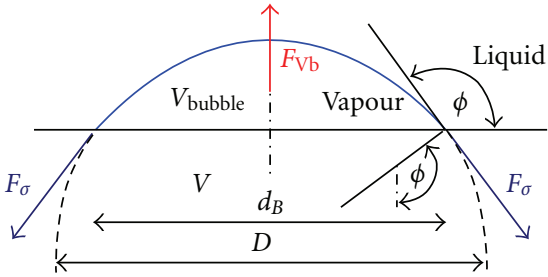

(b)

Figure 1: Spherical bubble in stagnant fluid on hydrophilic (a) and hydrophobic surface (b). $D$ stands for virtual bubble (sphere) defined with vapour slug interface curvature while $D_{\text {bubble }}$ stands for bubble departure diameter.

the intense vaporisation or/and intense condensation occurs due to the momentum transfer between the liquid and the vapour phase (Figure 3). Other agents, such as external force, virtual mass force, and wall lubrication force on the moving bubbles, may also take place during bubble growth and after departure.

Considering the Fritz [3] correlation, the equilibrium equation for the surface tension and the buoyancy force for the spherical bubble on the heating surface (Figure 1) can be written as

$$
\begin{aligned}
\sigma \cdot \pi \cdot D \cdot \sin \phi \\
\quad=\left(\rho_{l}-\rho_{v}\right) \cdot g \cdot \frac{\pi \cdot\left(2+3 \cos \phi-\cos ^{3} \phi\right)}{24} \cdot D^{3} .
\end{aligned}
$$

Hence bubble's sphere diameter can be expressed as

$$
D=\sqrt{\frac{24 \cdot \sin \phi}{\left(2+3 \cos \phi-\cos ^{3} \phi\right)} \cdot \frac{\sigma}{\left(\rho_{l}-\rho_{\nu}\right) \cdot g}} .
$$

Introducing the sphere volume to the vapour volume ratio, the base diameter to the sphere diameter ratio $(\sin \Phi)$, and the characteristic length into the equation above, one gets

$$
D=\sqrt{6 \cdot \frac{V}{V_{\text {bubble }}} \cdot \sin \phi} \cdot l_{0} .
$$

Assumption of the spherical bubble formation is justified with small vapour volumes generated on the heated surface. The smaller is the bubble, the higher is the relative pressure within the bubble. In fact, the smaller is the vapour volume, the more dominant is the surface tension force responsible for shaping the spherical bubble. As long as the generated vapour remains in contact with a solid wall, the slug takes over the shape of a spherical cup with considerably bigger sphere diameter particularly when hydrophobic surfaces are considered. Since the volume of the departing bubble is the same as the one of the spherical cup its diameter can be calculated as

$$
D_{\text {bubble }}=D \cdot\left(\frac{2+3 \cos \phi-\cos ^{3} \phi}{4}\right)^{1 / 3} .
$$

Rearranging (3) and (4) into (5) gives a more general expression for calculation of the bubble departure diameter that depends on the characteristic length and the contact angle:

$$
D_{\text {bubble }}=l_{0} \cdot\left(\frac{864 \cdot \sin ^{3} \phi}{2+3 \cos \phi-\cos ^{3} \phi}\right)^{1 / 6} .
$$

Equations (3) and (4) calculate virtual sphere diameter associated to the bubble interface curvature just before departure. Bubble departure diameter $D_{\text {bubble }}$ calculated in (5) and (6) together with the diameter of "sphere" is plotted in Figure 4 along with the data obtained from the Fritz correlation. Calculated results give rather different absolute values but they all show the tendency of increasing bubble diameter with contact angle. In fact, the more hydrophilic surface we adopt the smaller is the contact angle and thus the smaller is the surface tension force component acting toward the wall. The propensity of the hydrophilic surface to wet the exposed area with the liquid tends to displace bubbles at smaller size. Indeed, the smaller is the contact angle the smaller is the discrepancy between the calculated diameter of the growing bubble (virtual sphere) and the departing bubble. Despite monotonous increase of the bubble departure diameter with the contact angle, the geometry change from the growing bubble into the departing bubble becomes more significant at bigger contact angles. Therefore, prediction uncertainty has been analysed in order to validate the prediction capability of (4) and (6) over entire 


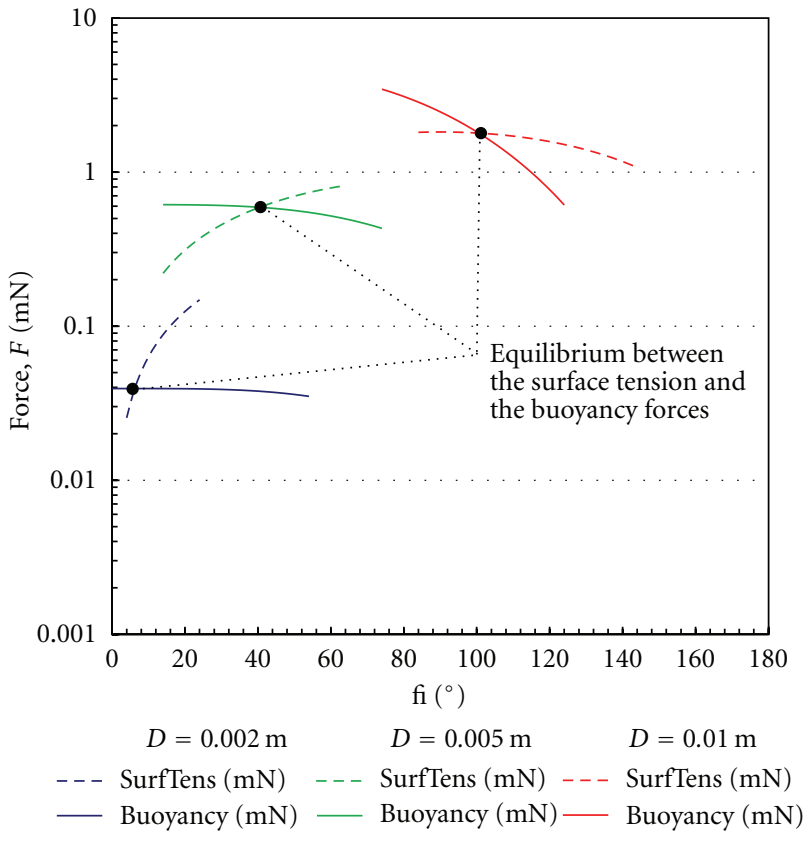

(a)

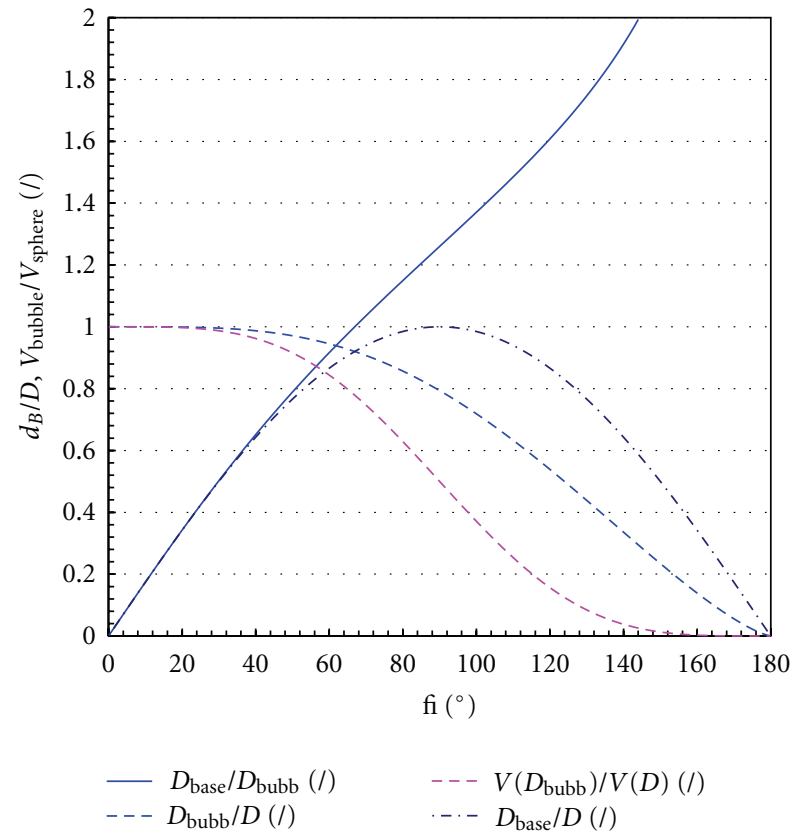

(b)

FIGURE 2: Surface tension and buoyancy force profiles for three different (virtual) bubble diameters over entire span of contact angles (a), and comparison of characteristic relative quantities (b).

span of contact angles. In this context, overall uncertainty has been calculated as

$$
\delta D_{\text {bubble }}=\sqrt{\sum_{i=1}^{n}\left(\frac{\partial D_{\text {bubble }}\left(x_{i}\right)}{\partial x_{i}} \cdot \delta x_{i}\right)^{2}},
$$

where partial derivatives of bubble departure diameter were derived as follows:

$$
\begin{gathered}
\frac{\partial D_{\text {bubble }}}{\partial \phi}=\frac{1}{2} \cdot 864^{1 / 6} \cdot\left(\frac{\sin ^{3} \phi}{2+3 \cos \phi-\cos ^{3} \phi}\right)^{7 / 6} \\
\cdot\left(\frac{\cos \phi \cdot\left(2+3 \cos \phi-\cos ^{3} \phi\right)}{\sin ^{4} \phi}+1\right) \cdot l_{0}, \\
\frac{\partial D_{\text {bubble }}}{\partial \sigma}=\frac{1}{2} \cdot\left(\frac{864 \cdot \sin ^{3} \phi}{2+3 \cos \phi-\cos ^{3} \phi}\right)^{1 / 6} \cdot l_{0} \cdot \frac{1}{\sigma}, \\
\frac{\partial D_{\text {bubble }}}{\partial \Delta \rho}=-\frac{1}{2} \cdot\left(\frac{864 \cdot \sin ^{3} \phi}{2+3 \cos \phi-\cos ^{3} \phi}\right)^{1 / 6} \cdot l_{0} \cdot \frac{1}{\left(\rho_{L}-\rho_{V}\right)}, \\
\frac{\partial D_{\text {bubble }}}{\partial g}=-\frac{1}{2} \cdot\left(\frac{864 \cdot \sin ^{3} \phi}{2+3 \cos \phi-\cos ^{3} \phi}\right)^{1 / 6} \cdot l_{0} \cdot \frac{1}{g} .
\end{gathered}
$$

Error band for a given surface contact angle was estimated to be $3^{\circ}$ whereas the variations in the surface tension and liquid to vapour density difference were obtained from the fluid property deviation associated to the measured temperature uncertainty of $0.3^{\circ} \mathrm{C}$. Indeed, density difference and surface tension variations for boiling water at atmospheric pressure were calculated as $10 \mathrm{~kg} \mathrm{~m}^{-3}$ and $0.64 \mathrm{mN} \mathrm{m}^{-1}$, respectively, while gravity variation was assumed $0.026 \mathrm{~m} \mathrm{~s}^{-2}$. However, a negligible contribution from the gravity associated variations can be observed in the Figure 5 .

Further to the critical assessment of the bubble departure diameter calculation similar analysis has been performed to estimate the reliability of the growing bubble (sphere) diameter prediction. Uncertainty values are plotted in Figures 4 and 5 for both bubble departure diameter and the diameter of the virtual sphere. Relative uncertainty of the spherical cup geometry prediction is monotonously decreasing and settles just beneath $1 \%$ at the highest contact angles, whereas the bubble departure diameter prediction error encounters global minimum of around $1.5 \%$ at moderately water repellent surfaces (Figure 5).

It can be seen from Figure 5 that prediction of the bubble departure diameter seems to give lower uncertainty values as compared to the growing bubble geometry but for the highest contact angles. In fact, the bubble departure diameter for the present boundary conditions (boiling water, 1 bar) is most accurately predicted on the hydrophobic surfaces with contact angles around $110^{\circ}$. Interestingly, deviation from defining the exact contact angles and the accurate fluid properties has a rather different effect on the final prediction accuracy of either bubble departure diameter or bubble growth geometry. Contact angle variation at the small nominal values, for example, has strong impact on both overall geometry uncertainties. On the contrary to the similar trend of the bubble departure diameter prediction capability at high contact angles, a negligible influence of the contact angle uncertainty is found at the highest nominal 


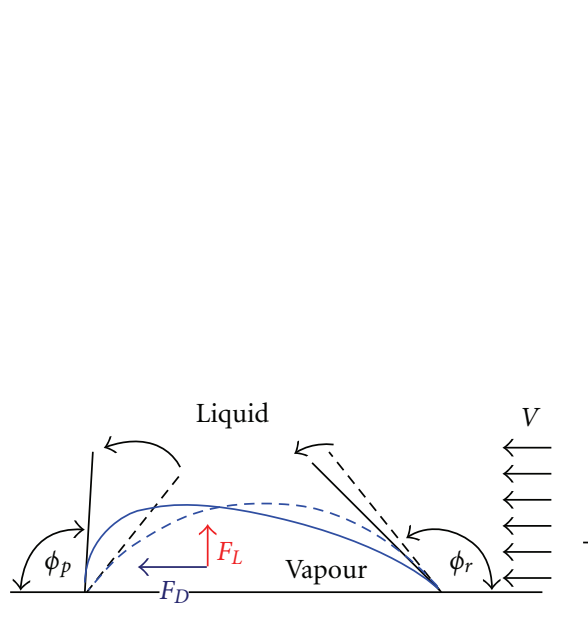

(a)

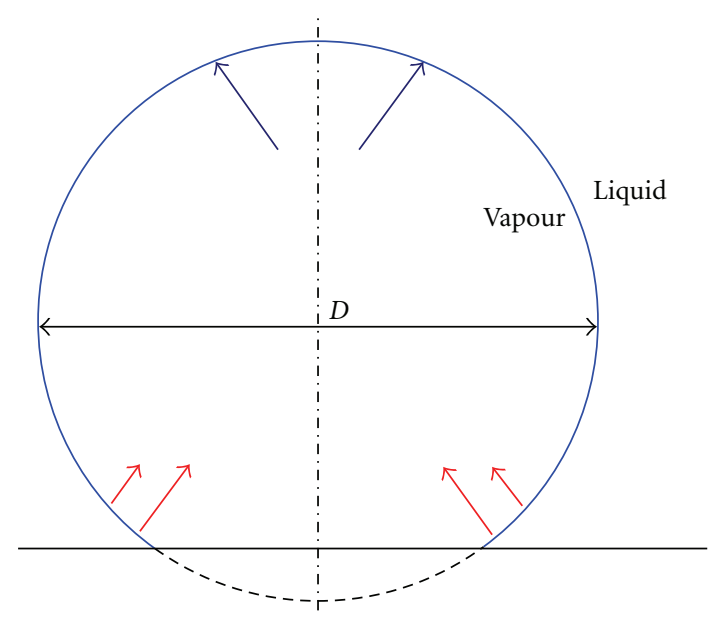

(b)

FIgURE 3: Demonstration of a drag force and a lift force acting on a vapour slug (a), and momentum change due to the evaporation and condensation on the liquid vapour interface within the bubble (b).

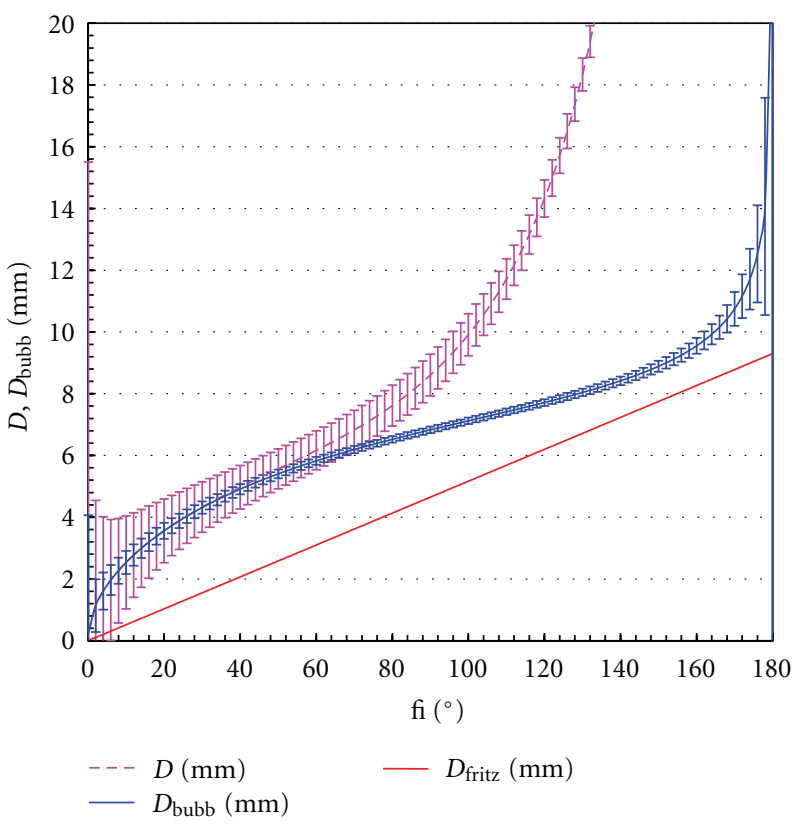

(a)

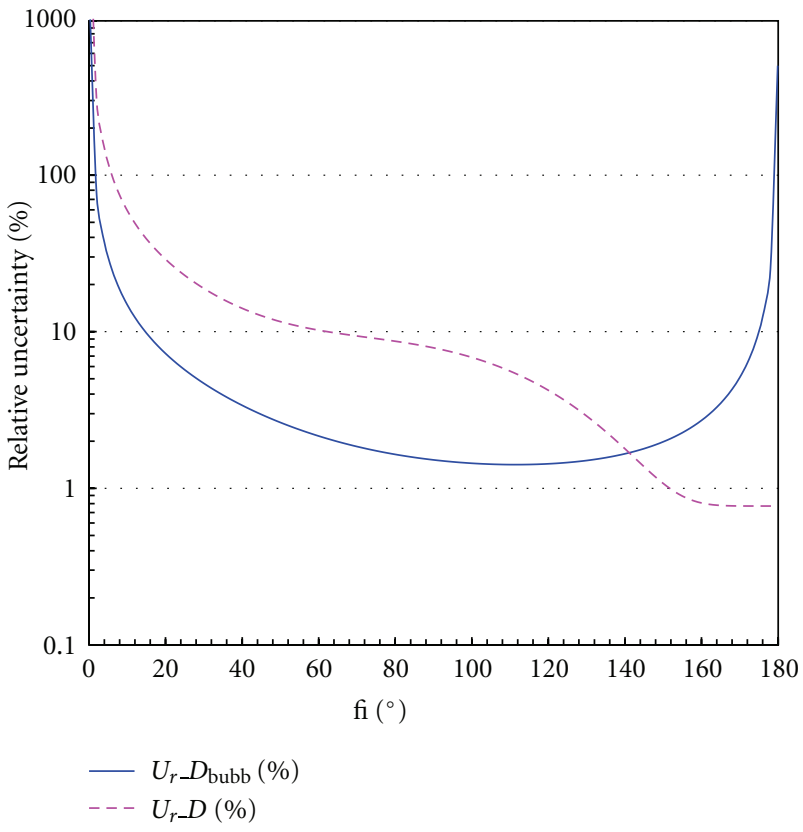

(b)

Figure 4: Calculated diameters with error bars for growing bubble (virtual sphere) and departing bubble with diameter calculated from Fritz correlation (a). Relative uncertainty of the calculated bubble departure diameter and virtual sphere diameter (b).

values when spherical cup geometry is analysed. Moreover, the smallest influence of the contact angle variation on the overall bubble departure diameter prediction uncertainty can be expected for moderate contact angles. It can be seen form Figure 5 that overall prediction uncertainty of the bubble departure diameter is entirely controlled with contact angle uncertainty. However, the same observation, but for the highest contact angles, can be drawn for calculated virtual sphere diameter. There, the surface tension and the density variation seem to take over the dominant contribution to overall uncertainty. Finally, gravity variation has been shown to have insignificant impact on the overall prediction uncertainty for growing and departing bubbles and over entire range of heating surfaces.

Figure 4 shows calculated bubble departure diameters by Fritz [3] and by (6) as well as the diameter of the growing bubble (virtual sphere). Error bars are depicting overall uncertainty values for the two geometries. It can be seen from Figure 4 that prediction ranges for bubble diameters calculated with either (4) or (6) are overlapping for contact 


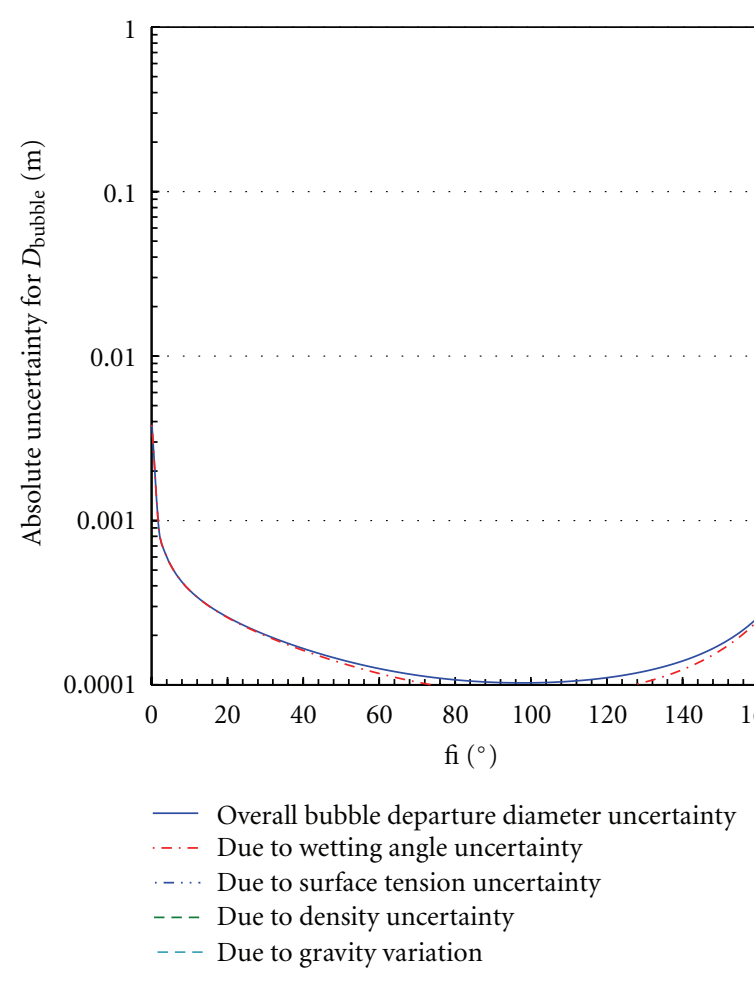

(a)

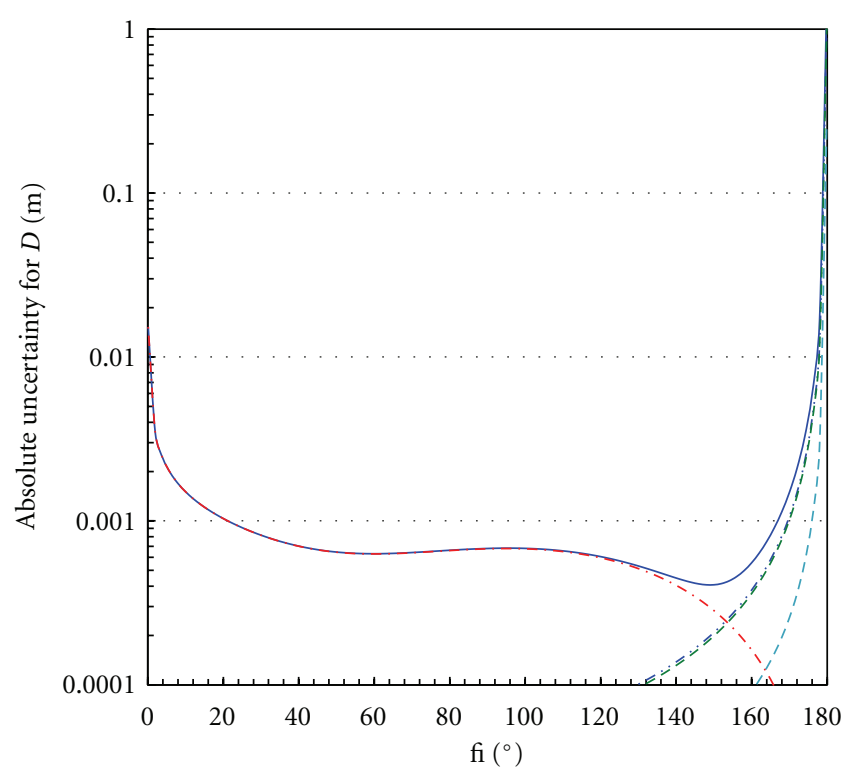

- Overall virtual bubble diameter uncertainty
$\ldots-$ Due to wetting angle uncertainty
$\ldots-\ldots$ Due to surface tension uncertainty
-- Due to density uncertainty
-- $\quad$ Due to gravity variation

(b)

FIGURE 5: Calculated uncertainty values for bubble departure diameter (a) and the diameter of the virtual sphere defined by the spherical cup (b).

angles smaller than $75^{\circ}$. Indeed, care must be taken at water repellent surfaces, to address appropriate bubble geometry in the calculus. Nevertheless, correlations based on mechanistic modelling of the two dominant mechanisms are not deemed highly effective for extreme contact angles.

\section{Conclusion}

Present paper presents qualitative estimation of the bubble departure diameter prediction modelling through the calculated uncertainty values over a wide range of test conditions. Despite some new notations of force balance the aim of this study is not to offer another correlation for bubble diameter prediction but to give critical arguments for quality assessment of the existing modelling. In fact, the main purpose of the present work was to offer a methodological approach that would help estimating the prediction constraints of the chosen correlations. It has been shown that the inlet boundary conditions with a realistic experimental accuracy may lead to a significant deviation in prediction of bubble departure and bubble growth diameters even in the absence of the fluid motion. Uncertainty values for bubble departure diameter correlation were calculated below 3\% for most of the heating surfaces. On the other hand, despite monotonously decreasing relative uncertainty of the growing bubble (virtual sphere), it gives higher uncertainty values for most contact angles but on highly water repellent surfaces. Intuitively one can expect that introduction of new driving mechanisms in the modelling would further increase the prediction uncertainty.

\section{References}

[1] R. T. Lahey, "A mechanistic Subcooled boiling model," in Proceedings of the 6th International Heat Transfer Conference, vol. 1, Toronto, Canada, 1978.

[2] N. Kurul and M. Z. Podowski, "Multidimensional effects in forced convection subcooled boiling," in Proceedings of the 9th International Heat Transfer Conference, Jerusalem, Israel, 1990.

[3] W. Fritz, "Maximum volume of vapor bubbles," Physikalische Zeitschrift, vol. 36, pp. 379-384, 1935.

[4] R. Cole and W. Rohsenow, "Correlation of bubble departure diameters for boiling of saturated liquids," Chemical Engineering Progress, vol. 65, pp. 211-213, 1969.

[5] V. I. Tolubinski and D. M. Kostanchuk, "Vapor bubbles growth rate and heat transfer intensity at subcooled water boiling," in Proceedings of the 4th International Heat Transfer Conference, vol. 5, Paper no. B2.8, Paris-Versailles, France, 1970.

[6] G. Kocamustafaogullari, "Pressure dependence of bubble departure diameter for water," International Communications in Heat and Mass Transfer, vol. 10, no. 6, pp. 501-509, 1983.

[7] D. Gorenflo, V. Knabe, and V. Bieling, "Bubble density on surfaces with nucleate boiling-it's influence on heat transfer and burnout heat fluxes at elevated saturation pressures," in Proceedings of the 8th International Heat Transfer Conference, vol. 4, pp. 1995-2000, Hemisphere, Wash, USA, 1986.

[8] C. E. Estrada-Perez and Y. A. Hassan, "PTV experiments of subcooled boiling flow through a vertical rectangular 
channel," International Journal of Multiphase Flow, vol. 36, no. 9, pp. 691-706, 2010.

[9] V. K. Dhir, "Mechanistic prediction of nucleate boiling heat transfer-achievable or a hopeless task?" Journal of Heat Transfer, vol. 128, no. 1, pp. 1-12, 2006.

[10] Y. Nam, E. Aktinol, V. K. Dhir, and Y. S. Ju, "Single bubble dynamics on a superhydrophilic surface with artificial nucleation sites," International Journal of Heat and Mass Transfer, vol. 54, no. 7-8, pp. 1572-1577, 2011.

[11] G. J. Kirby, R. Stainiforth, and L. H. Kinner, "A visual study of forced convection boiling-2: flow patterns and burnout for a round test section," Tech. Rep. AEEW-R-506, UKAEA, Winfrith, UK, 1967. 

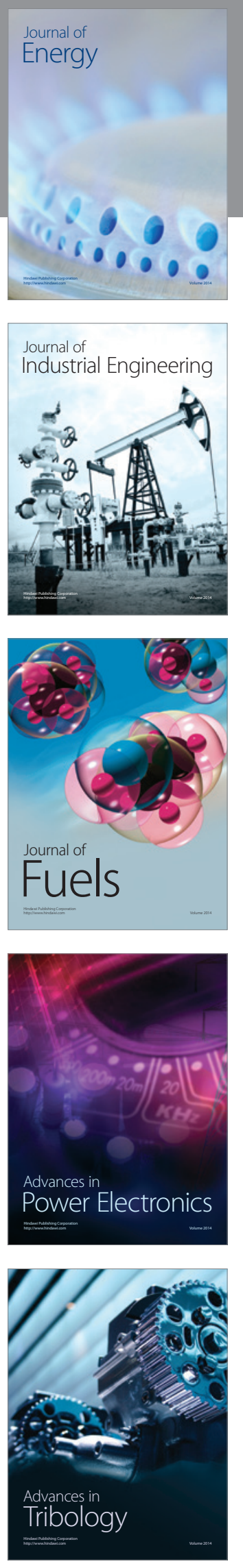
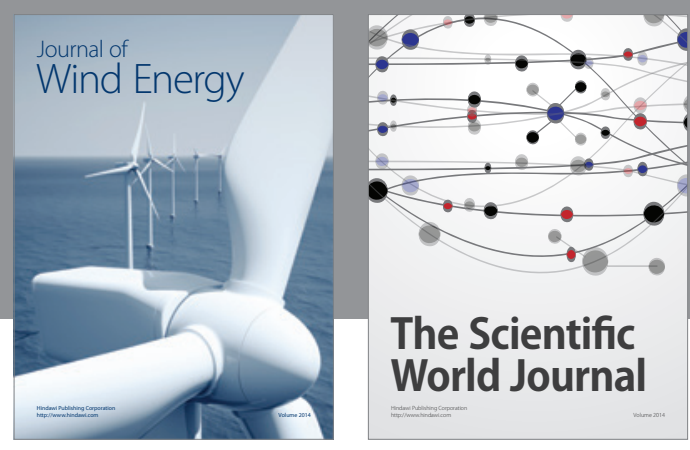

The Scientific World Journal

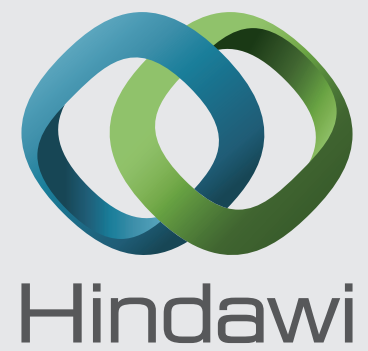

Submit your manuscripts at http://www.hindawi.com
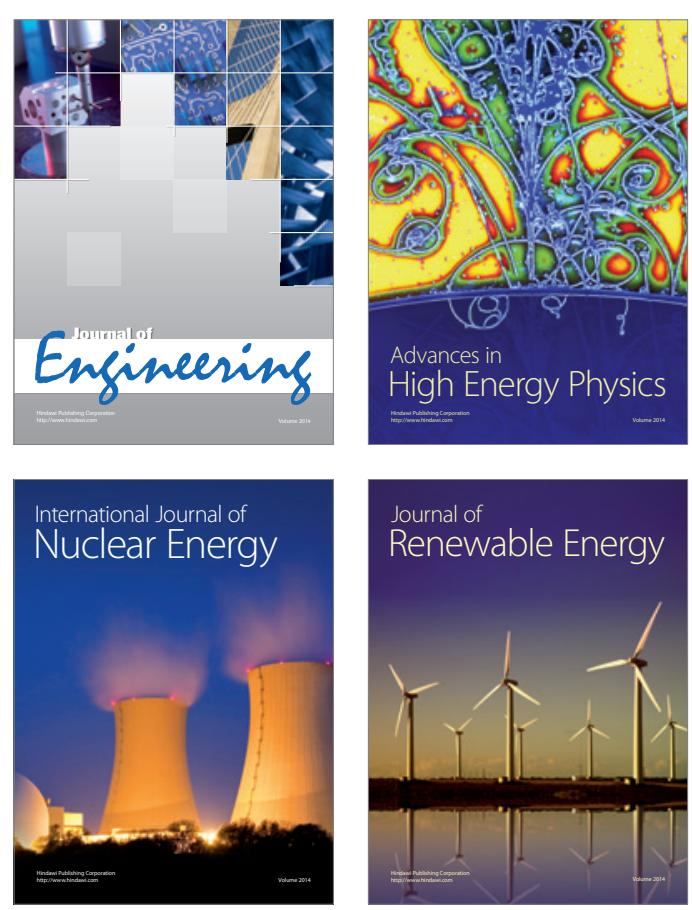

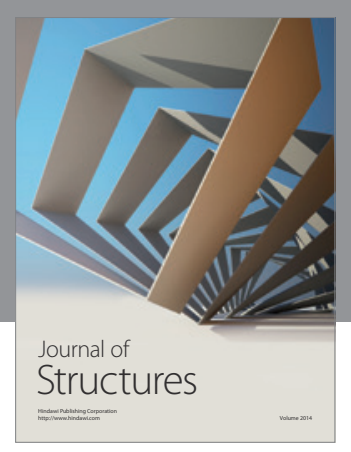

Rotating
Mechinery
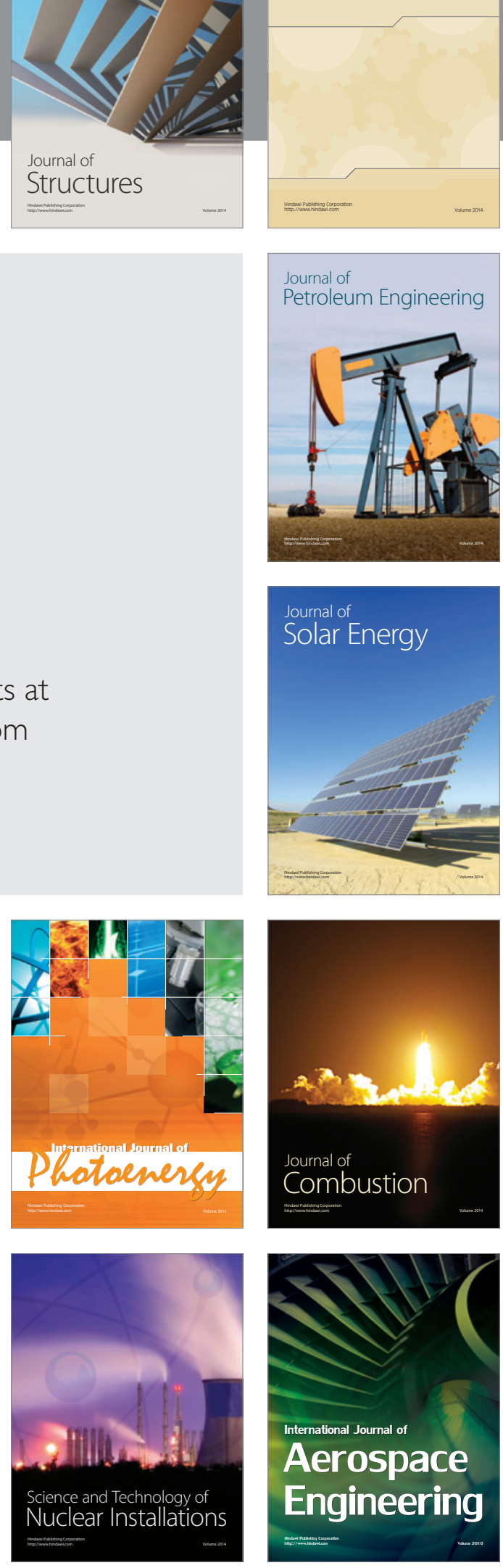